\begin{tabular}{|l|l|l||}
\hline \multicolumn{2}{|c|}{ PublisherInfo } \\
\hline \hline PublisherName & $:$ & BioMed Central \\
\hline \hline PublisherLocation & $:$ & London \\
\hline \hline PublisherImprintName & $:$ & BioMed Central \\
\hline \hline
\end{tabular}

\title{
Tamoxifen and response
}

\begin{tabular}{|l|l|l||}
\hline \multicolumn{2}{|c|}{ ArticleInfo } \\
\hline \hline ArticleID & $:$ & 3713 \\
\hline \hline ArticleDOI & $:$ & $10.1186 /$ bcr-2000-66676 \\
\hline \hline ArticleCitationID & $:$ & 66676 \\
\hline \hline ArticleSequenceNumber & $:$ & 79 \\
\hline \hline ArticleCategory & $:$ & Paper Report \\
\hline \hline ArticleFirstPage & $:$ & 1 \\
\hline \hline ArticleLastPage & $:$ & 4 \\
\hline \hline & & RegistrationDate : 2000-5-17 \\
\hline ArticleHistory & $:$ & OnlineDate \\
\hline \hline ArticleCopyright & $:$ & Current Science Ltd2000-5-17 \\
\hline \hline ArticleGrants & $:$ & \\
\hline \hline ArticleContext & $:$ & 1305822 \\
\hline \hline
\end{tabular}


Valerie Speirs, ${ }^{\text {Aff1 }}$

Aff1 Molecular Medicine Unit, University of Leeds, UK

\section{Keywords}

4-hydroxytamoxifen, desmethyltamoxifen, response, tamoxifen

\section{Introduction}

The non-steroidal anti-oestrogen TAM is currently first line therapy for treatment of hormonedependent breast cancer. However, despite initial benefits, most patients eventually relapse. Acquired resistance is likely to be multifactorial, but as yet this is incompletely understood. A number of theories have been proposed, including local metabolism of TAM to less potent or unstable metabolites, loss/ mutation of target oestrogen receptor (ER) or altered signal transduction. Overexpression of transforming growth factor (TGF)- $\beta 1$ and alterations in protein kinase A signalling pathways have also been implicated. Mutations in ER $\alpha$ and more recently overexpression of ER $\beta$ have also been considered.

\section{Aims}

This pharmacological study measured levels of TAM and its metabolites 4-hydroxytamoxifen (4OH) and desmethyltamoxifen (DMT) in plasma and tumour tissue from patients undergoing primary neoadjuvant therapy. These levels were correlated with patient response.

\section{Comments}

Despite the clear benefits of tamoxifen (TAM) in extending disease-free and overall survival of breast cancer patients, the development of anti-oestrogen resistance remains a considerable clinical problem. A pharmacological approach was used to determine if plasma and tumour levels of TAM and its metabolites differ in TAM-sensitive and -resistant breast cancer patients. While there was no direct correlation of patient response with tumour/plasma levels of TAM or its metabolites, this probably reflects the fact that multiple factors are likely to be involved in the development of TAM resistance. Although measurement of plasma/tumour TAM may be of value in assessing drug accumulation at 
target sites, more detailed assessment at the cellular level is necessary to predict the development of a resistant phenotype.

\section{Methods}

Patients treated with TAM (20 mg per day) for at least 3 months were categorised into three groups according to their response: tumours decreasing in size with continual reduction, or decreasing then showing no change (TAM responders); tumours initially reducing in size but which subsequently increased in size (acquired TAM resistance); and tumours remaining the same size or increasing in size during treatment (de novo TAM resistance). Response was monitored by monthly ultrasound and clinical measurement. Aliquots of plasma $(1 \mathrm{ml})$ or tumour $(0.5 \mathrm{mg})$ from these three cohorts were applied to an activated solid-phase high performance liquid chromatography (HPLC) column and the concentration of TAM and its metabolites measured. These were correlated with clinical response, length of treatment and patient weight.

\section{Results}

Overall, TAM levels were wide ranging in the three patient groups, possibly reflecting tumour heterogeneity; however, a number of trends were evident. There were no significant accumulations of plasma or tumour TAM/DMT over time, although levels of the active metabolite $4 \mathrm{OH}$ increased in all three patient groups. In the acquired TAM resistance group, there was a continuous accumulation of drug over time with lower levels observed in TAM responders. Lower levels of TAM and its metabolites were also observed in ER-depleted tumours. Investigations into the inter-relationships between metabolites revealed a positive correlation between TAM and $4 \mathrm{OH}$ in the de novo resistant group. In contrast, TAM responders and acquired TAM resistant tumours showed no correlation between TAM and DMT. No significant correlations were observed between weight of patients and levels of $4 \mathrm{OH}$ or DMT, although TAM levels increased with increasing weight and time in tumours with acquired resistance.

\section{Discussion}

In general, measurement of TAM and its metabolites in breast tumours does not appear to correlate with clinical response in the majority of patients. However the accumulation of $4 \mathrm{OH}$ with increased treatment time may be associated with development of resistance, perhaps allowing the clonal expansion of resistant cells. 


\section{References}

1. Singer JM, Price P, Dale RG: Concentrations of tamoxifen and its major metabolites in hormone responsive and resistant breast tumours. Br J Cancer. 2000, 82: 1629-1635.

This PDF file was created after publication. 